\title{
A novel low molecular weight nanocomposite hydrogel formulation for intra- tumoural delivery of anti-cancer drugs
}

Ivana Štakaa,b,c; Ana Cadetea; Bhanu Teja Surikutchic; Haneen Abuzaidb; Tracey D. Bradshaw ${ }^{\mathrm{b}}$; Maria J Alonso ${ }^{a^{*}} ;$ Maria Marlow ${ }^{c^{*}}$

5 aCIMUS Research University, University of Santiago de Compostela, 15706 Campus Vida, Spain; bentre for Biomolecular Sciences, University of Nottingham, NG7 2RD, UK; 'Boots Science Building, School of Pharmacy, University of Nottingham, NG7 2RD, UK.

*Corresponding authors: maria.marlow@nottingham.ac.uk and mariaj.alonso@usc.es

Keywords: gel-nanocomposite; polymeric nanocapsules; low molecular weight gelators; local delivery

Herein, an injectable formulation composed of a low molecular weight gelator (LMWG) based hydrogel and drug-loaded polymeric nanocapsules (NCs) is described. The NCs, made of hyaluronic acid and polyglutamic acid and loaded with C14-Gemcitabine (GEM C14), showed a size of 40 and $80 \mathrm{~nm}$ and a encapsulation efficiency $>90 \%$. These NCs exhibited a capacity to control the release of the encapsulated drug for more than 1 month. GEM C14-loaded NCs showed activity against various cancer cell lines in vitro; cell growth inhibition by $50 \%\left(\mathrm{Gl}_{50}\right)$ values of $15 \pm 6,10 \pm 9,13 \pm 3$ and $410 \pm 463 \mathrm{nM}$ were obtained in HCT 116, MIA PaCa-2, Panc-1 and Panc-1 GEM resistant cell lines respectively. Nanocomposite hydrogels were prepared using the LMWG - N4-octanoyl-2'-deoxycytidine and loaded for the first time with polymeric NCs. $2 \%$ and $4 \% \mathrm{w} / \mathrm{v}$ nanocapsule concentrations as compared to $8 \% \mathrm{w} / \mathrm{v} \mathrm{NC}$ concentrations with $2 \%$ and $3 \% \mathrm{w} / \mathrm{v}$ gelator concentrations gave mechanically stronger gels as determined by oscillatory rheology. Most importantly, the nanocomposite formulation reformed instantly into a gel after injection through a needle. Based on these properties, the nanocomposite gel formulation has potential for the intratumoural delivery of anticancer drugs.

${ }_{1}$ Abbreviations: low molecular weight gelator (LMWG); nanocapsules (NCs); N4-myristoyl gemcitabine 25 (GEM C14); low molecular weight (LMW); hexadecyltrimethylammonium bromide (CTAB); Sodium hyaluronate (HA); poly-L-glutamic acid (PGA); GEM hydrochloride (GEM-HCl); 9-Diethylamino-5Hbenzo[a]phenoxazine-5-one - Nile Red (NR); Linear visco-elastic (LVE) region; GEM resistant cell line (GEM R Panc-1). 


\section{Introduction}

Supramolecular gels are formed from low molecular weight (LMW) molecules (typically $<3 \mathrm{kDa}$ ). The main characteristic of low molecular weight gelators (LMWG) is their ability to gel solvent (water in the case of hydrogels) at concentrations as low as $0.5 \%$ wt through the process of self-assembly and the formation of fiber networks (Sangeetha and Maitra, 2005). The self-assembly is governed by non-covalent physical interactions whose dynamic nature can bring two features: viscous flow under shear stress (shear-thinning) and time-dependent recovery upon relaxation (self-healing) (K.J. Skilling et al., 2016). These properties make supramolecular gels appropriate for an injectable formulation.

The design of LMWGs for cancer therapy has been increasingly reported over the last decade. Specifically, peptide-type LMWGs have been extensively investigated and used for incorporation of various cancer drugs such as doxorubicin (DOX) (Naskar et al., 2009), campthothecin (Cheetham et al., 2013), paclitaxel (Wang et al., 2011) and many others (Tian and Niu, 2014). Additionally, LMWG gel formulations, oligopeptides, lanreotide and degarelix composed of 8 and 10 amino acids respectively, are used clinically as hormone therapy in patients with neuroendocrine tumours (Pokuri et al., 2016; Steinberg 2009; Klotz et al., 2008; Vlieghe et al., 2010). Several LMWG formulations, specifically designed for intra-tumoural delivery of anticancer drugs have shown inhibition of tumour growth. For example, DOX was physically entrapped in a gel made of L-alanine hydrazide gelator and was reported to reduce the tumour burden by $40 \%$ as compared to an untreated control when injected into a breast (4T1) tumour model in mice, whereas DOX alone had negligible antitumour effects upon injection (Singh et al., 2014). In another example, a Taxol derivative (succinic acid - glutathione) self-assembled into an injectable hydrogel and impeded tumour growth 2-fold compared to an i.v. injection of Taxol® in the breast (4T1) tumour model in mice. Furthermore, the Taxol hydrogel was able to prevent metastasis. Additionally, the fatal dose of Taxol® in this hydrogel was shown to be at least 7.5x higher than that of $\operatorname{Taxo}^{\circledR}$ (Wang et al., 2012).

Based on the apparent success of gel formulations for the intratumoural delivery of anticancer drugs, the objective of this work was to design and develop a new nanocomposite hydrogel formulation consisting of a nucleoside based LMWG and polymeric coated nanocapsules (NCs). Considering that a variety of late stage cancers cannot be surgically removed, (e.g. pancreatic and oesophageal cancers), it has been hypothesized that their treatment could benefit from such a drug delivery platform. The gel structure should ensure localised drug delivery over many cell cycles (Wolinsky et al., 2012) and the incorporation of NCs may provide opportunities for increased tumour permeation of drug, beyond that of diffusion from the gel (Strasser et al., 1995). Examples of such nanocomposite gels include: association of poly(ethylene glycol)block-poly(-lactic acid) (PEG-b-PLA) NPs with hydroxypropylmethylcellulose (HPMC) gels (Appel et al., 2015), Eudragit NCs (Contri et al., 2014), poly(d,I- lactide)-b-(ethyleneoxide) (PLA-b-PEO) NPs (Grant et al., 2005) and chitosan NPs (Şenyiğit et al., 2015) with chitosan gels, poly( $\varepsilon$-caprolactone)- poly(ethylene glycol)-poly( $\varepsilon$-caprolactone) (PCEC) NPs with Pluronic F127 gels (Gou et al., 2008) and some liposomal formulations with PEG gels (Lalloo et al., 2006). In comparison to polymer gels, LMWG are hypothesized 
to have a different mechanism of release and pore structure and hence should be evaluated as a viable alternative to the extensively explored polymeric nanocomposite gels.

More precisely, in this work the association of N4-octanoyl-2'-deoxycytidine gels with polymer coated NCs loaded with N4-myristoyl gemcitabine (GEM C14), is presented as a delivery strategy of potential application for the treatment of non resectable tumours. A lipophilic (4- $(M$ position modification) form of gemcitabine was selected to overcome the short half-life and acquired resistance of the parent compound (Mackey et al., 1998; Weizman et al., 2014; Pulido et al., 2014). Additionally, the hydrophobic modification of gemcitabine further allowed its encapsulation in the lipid core of NCs.

The selection of the drug nanocarrier to be include in the gel was based on our previous experience with polymeric NCs (Oyarzun-Ampuero et al., 2013; Rivera-Rodriguez et al., 2013; Lollo et al., 2015), (Janes et al., 2001; Torrecilla et al., 2013),(Rivera-Rodriguez et al., 2013), (Gonzalez-Aramundiz et al., 2017) (PGAPEG) (Borrajo et al., 2016). Hyaluronic acid (HA) and polyglutamic acid (PGA) nanocapsules were chosen as a good option based on previous studies showing their activity in vitro and in vivo (Orzayon-Ampuero et al., 2013; Lollo et al., 2015). Firstly these NCs were optimised for our application and their ability to inhibit cancer cell growth evaluated in vitro using cancer cell lines including a GEM-resistant pancreatic cell line as drug resistance presents a major problem thwarting successful cancer treatment (Hong et al., 2009; Long et al., 2011). Finally, the formation and characterisation of a nanocomposite formulation, of NCs and a LMWG based hydrogel was assessed.

\section{Methods}

\subsection{Materials}

85 Miglyo $^{\circledR} 812 \mathrm{~N}$ oil - medium chain triglyceride (MCT) was kindly donated by CREMER OLEO GmbH \& Co. Surfactants: Kolliphor ${ }^{\circledR}$ HS 15 (PEG-660-12 hydroxystearate) was kindly provided by BASF ChemTrade $\mathrm{GmbH}$; Tween ${ }^{\circledR}$ 80- polyoxyethylene sorbitan monooleate and hexadecyltrimethylammonium bromide (CTAB) were purchased from Sigma. Polymers: Sodium hyaluronate $50 \mathrm{kDa}$ (HA, LifeCore biomedical); poly-L-glutamic acid sodium salt $5 \mathrm{kDa}$ - (PGA, Sigma). Drug GEM hydrochloride (GEM-HCl) was purchased from Sigma. N4-myristoyl gemcitabine (GEM C14) and low molecular weight gelator: N4octanoyl-2'-deoxycytidine were synthesised as previously reported (KJ. Skilling et al., 2018; K.J. Skilling et al., 2016). Fluorescent dye 9-diethylamino-5H-benzo[a]phenoxazine-5-one - (Nile Red) was purchased from MP Biomedical.

\subsubsection{Reagents used for in vitro cell culture}

95 Cell culture medium-RPMI 1640, phosphate buffer serum (PBS), foetal bovine serum (FBS, F7524); trypsin; 3-(4,5-dimethylthiazol-2-yl)-2,5-diphenyltetrazolium bromide (MTT), methylene blue and the solvent DMSO were purchased from Sigma and used without further purification. 
For the preparation of drug release dissolution medium, phosphate buffered saline (PBS) in the form of tablets were purchased from Sigma. One tablet was dissolved in $200 \mathrm{~mL}$ of deionised water yielding 0.01 $\mathrm{M}$ phosphate buffer, $0.0027 \mathrm{M}$ potassium chloride and $0.137 \mathrm{M}$ sodium chloride, $\mathrm{pH} 7.4$, at $25^{\circ} \mathrm{C}$.

\subsection{Manufacture and characterization of nanocapsules}

Polymeric NCs were produced by a self-emulsifying method that requires addition of an oil phase to aqueous phase under gentle agitation. Blending the oil, surfactants and drug (oil phase) in appropriate ratios at low heat $\left(40-50^{\circ} \mathrm{C}\right)$ until all were solubilised and then dispersing them directly in polymer solution (aqueous phase) at room temperature (RT) produces spontaneously oil-in-water NCs. The oil phase consisted of 70 or $53 \mathrm{mg}$ of Miglyol ${ }^{\circledR} 812 \mathrm{~N} ; 45$ or $53 \mathrm{mg}$ of Kolliphor ${ }^{\circledR} \mathrm{HS} 15 ; 45$ or 53 mg of Tween ${ }^{\circledR} 80$ and $0.25 \mathrm{mg}$ of $\mathrm{CTAB}$ as surfactants per $\mathrm{A}$ or $\mathrm{B}$ formulation respectively. In addition, the oil phase contained $(0.1 \% \mathrm{w} / \mathrm{w})$ of drug GEM C14. The aqueous phase consisted of $2 \mathrm{mg} / \mathrm{mL}$ polymer solution of HA or PGA in pure deionised water (Milli-Q). The aqueous phase:oil phase ratio was 1:8 (w:w).

\subsubsection{Physicochemical characterisation of NCs}

The average diameter and polydispersity index (PDI) of NCs were characterised by dynamic light scattering after diluting the samples 3:100 (v:v) with Milli-Q water. Zeta potential (ZP) was determined by laser Doppler micro-electrophoresis after 5:100 (v:v) sample dilution with Milli-Q water. The measurements were performed on a Malvern ZetaNano ZS, UK.

115 Encapsulation efficiency was calculated as percentage of the drug in the isolated NCs compared to the total amount of the drug in NCs before the isolation. NCs were separated from the free drug using size exclusion chromatography columns (SEC) - Zetadex 25M, CentriPure P10. Columns were prepared according to the manufacture's protocol.

Colloidal stability of GEM C14 loaded NCs was assessed upon storage at room temperature (RT) or in the fridge $\left(8^{\circ} \mathrm{C}\right)$ for up to 4 weeks. In addition, colloidal stability was assessed upon incubation in PBS as well as in the cell culture medium (RPMI 1460) used in the in vitro cell culture studies. The dilution factor in these studies was $1: 10(\mathrm{v} / \mathrm{v})$.

\subsubsection{In vitro release of GEM C14 from NCs}

The procedure for in vitro drug release involved incubation under sink condition of $0.5 \mathrm{~mL}$ GEM C14-loaded NCs $(0.1 \%)$ with $37.5 \mathrm{~mL}$ of release medium in a water bath at $37^{\circ} \mathrm{C}$ with agitation at $100 \mathrm{rpm}$.. Other volumes of release medium were employed, $12.5,24.5$ and $37.5 \mathrm{~mL}$, where the latter two showed negligible effects on the released amount, hence further dilutions were not explored. At predetermined time intervals $1 \mathrm{~mL}$ of sample was taken and the separation of the free drug from the NCs was performed by size exclusion chromatography (SEC). The sample was replaced with $1 \mathrm{~mL}$ of PBS. The percentage cumulative release was calculated indirectly using the following equation: 


$$
\% \text { cumulative release }=\frac{X i-X t}{X i} \times 100
$$

where $\mathrm{Xi}$ is the amount initially loaded into NCs and Xt the amount that is in NCs at time point. As drug released was below the detection limit, by measuring the drug retained within NCs, the amount of drug released could be indirectly calculated. The small amount discarded at each time point when removing sample and replacing it with PBS was added to the amount released.

Quantification of GEM C14 by HPLC was carried out using a method based on those already reported in the literature (Bastiancich et al., 2016; Immordino et al., 2004). Briefly, GEM C14 and GEM C14 loaded NCs were dissolved in methanol and an aliquot was injected into a HPLC system consisting of an ACE 5 C18 $5 \mu \mathrm{m} ; 75 \times 4.6 \mathrm{~mm}$ column followed by isocratic elution ( $80 \%$ methanol, $20 \%$ pure water) at $30{ }^{\circ} \mathrm{C}$, under constant flow rate of $1 \mathrm{~mL} / \mathrm{min}$ and UV detection at $248 \mathrm{~nm}$. These conditions gave a retention time of around 7.8 minutes. The standard calibration curve of GEM C14 was linear (R2 > 0.999) in the range of concentrations between and 0.5 and $50 \mu \mathrm{g} / \mathrm{mL}$.

\subsubsection{In vitro activity of drug-loaded NCs in cancer cells}

GEM C14-loaded NCs were manufactured as described above and were assessed for in vitro cell growth inhibition on cancer cell lines. Eight formulations (HA 80, HA 40, PGA 80 and PGA 40 nm NCs blank or loaded with GEM C14) were tested and compared with GEM C14 and GEM hydrochloride (GEM-HCI). The initial concentration of GEM C14 in NCs was $~ 25 \mu \mathrm{M}$. Blank NCs did not contain drug. Human carcinoma cell lines used in experiments were the HCT 116 colorectal and MIA Paca-2, Panc-1 and GEM-resistant Panc-1 pancreatic cancer cell lines. Human carcinoma cell lines (HCT 116, MIA Paca-2 and Panc-1) were all sourced from the American Type Culture Collection (ATCC).

General cell culture involved incubation of serially sub-cultured cells at $37^{\circ} \mathrm{C}$ in a humidified atmosphere of $95 \%$ air and $5 \% \mathrm{CO}_{2}$. Cells were grown in RPMI 1640 medium supplemented with $10 \% \mathrm{v} / \mathrm{v}$ FBS. Once cells had reached approximately $70 \%$ confluence they were used for the experiments. A pancreatic GEMresistant cell line was generated by continuous culture of parental Panc-1 cells in medium supplemented with incremental gemcitabine concentrations, and then maintained in medium spiked with $1 \mu \mathrm{M}$ Gemcitabine. This cell line was developed and kindly donated by Dr Lodewijk Dekker (University of Nottingham).

\subsubsection{Growth inhibition assay}

The MTT assay was used for mitochondrial activity evaluation, a surrogate marker for viable cell number.

Briefly, cells were seeded into 96 -well plates at a density of $3 \times 10^{3}$ cells/well in $180 \mu \mathrm{L}$ of culture medium. An extra plate was prepared containing cells from each cell line in order to carry out an MTT assay at the time the cells were treated. This allows the initial optical density (OD) to be determined. After $24 \mathrm{~h}$, cells were treated with drug alone (GEM C14 and GEM-HCl), blank NCs and GEM C14-loaded NCs starting with 
GEM concentration from $25 \mu \mathrm{M}$ followed by 10 -fold serial dilutions. Four wells were used for each condition. Control cells were treated with medium alone. Following $72 \mathrm{~h}$ incubation, $50 \mu \mathrm{L}$ of $2 \mathrm{mg} / \mathrm{mL}$ MTT solution were added to each well. Cells were incubated for a further $2.5 \mathrm{~h}$ to allow formazan production. The aqueous medium was then aspirated and the formazan product solubilised in DMSO (150 $\mu \mathrm{L} /$ well). Absorbance at $570 \mathrm{~nm}$ (optical density - OD570) was read using an EnVision 2104 Multilabel Reader. The concentrations at which cell growth is inhibited by $50 \%\left(\mathrm{Gl}_{50}\right)$ were calculated from the dose-response curves estimated by linear interpolation between two closest values after taking into account the initial optical density acquired at the time of treatment. MTT assays were carried out on $\geq 3$ separate occasions and mean $\mathrm{Gl}_{50}$ values were calculated.

\subsubsection{Gel-NC composites for localised cancer therapy}

N4-octanoyl-2'-deoxycytidine was used as LMWG as it was reported to gel in pure water using a heatingcooling cycle as the method for gel formation (Skilling et al., 2016). A defined amount of gelator was added to water and heated in a water bath up to $60^{\circ} \mathrm{C}$ until the compound completely dissolved. The sample was then allowed to cool to room temperature for $~ 30$ minutes. For the preparation of gel-NCs composite, the procedure was the same except that the gelator was dissolved in NCs formulation instead of in pure water. The following concentrations of LMWG were investigated: $0.5,1,1.5,2,2.5,3,3.5$ and $4 \%$ (w/v). All 4 NCs formulations were tested (HA 80, HA 40, PGA 80 and PGA $40 \mathrm{~nm} \mathrm{NCs).} \mathrm{HA} 80 \mathrm{~nm}$ NCs were tested at concentrations of $8 ; 4$ and $2 \% \mathrm{w} / \mathrm{v}$. For the comparison among different NCs, all NCs` formulations at a concentration of $4 \% \mathrm{w} / \mathrm{v}$ were formulated with a $2 \% \mathrm{w} / \mathrm{v}$ gelator concentration.

\subsubsection{Measurement of storage and loss modulus}

Oscillatory rheology was carried out using an Anton Paar MCR302 Modular Compact Rheometer using a cup and vane geometry. Gel sample $(2 \mathrm{~mL}$ ) was placed in a disposable measuring Cup EMB-Z4 (Anton Paar) which was set into the lower part of the rheometer (cup). The upper part of the rheometer (vane) was positioned into the centre of the gel at a depth of $2 \mathrm{~mm}$. All gel samples were prepared 1 day before the rheological measurement. Oscillatory amplitude sweep measurements were carried out at strains varying between $0.05-100 \%$. The G'and G" (storage modulus and loss modulus, respectively) were measured at

190 a constant angular frequency of $10 \mathrm{rad} / \mathrm{s}$. The temperature was set to $37^{\circ} \mathrm{C}$ to mimic physiological conditions. The linear visco-elastic (LVE) region was calculated using Rheoplus Anton Paar software where deviation from linearity was $<3-6 \%$.

\subsubsection{Release of the NCs from the gel-NCs composite}

Nile Red (NR) loaded NCs were used in the in vitro release experiments of NCs from the gel nanocomposite formulation. The preparation of NR-loaded NCs involved addition of ethanol solution containing NR into the oil phase. After blending all components together, the oil phase plus dye, was stirred for several hours at $80^{\circ} \mathrm{C}$ to ensure that all ethanol had evaporated. NCs were formulated, as previously described by dispersing oil phase into polymer solution under magnetic stirring. The final theoretical NR concentration in 
NCs was $\sim 10 \mu \mathrm{g} / \mathrm{mL}$. The size of NCs loaded with dye was determined using the Zeta sizer as previously described.

Release of NR-loaded NCs from the gel system was performed in a similar way as from NCs. The gelator ( $2 \% \mathrm{w} / \mathrm{v})$ was formulated with $8 \%$ w/v HA $80 \mathrm{~nm} \mathrm{NCs;} 4 \%$ w/v HA $80 \mathrm{~nm} \mathrm{NCs}$ or $4 \% \mathrm{w} / \mathrm{v} \mathrm{HA} 40 \mathrm{~nm}$ NCs loaded with NR. Gels were formulated with $0.5 \mathrm{~mL}$ of NCs 1 day before the experiment and then topped up with $12.5 \mathrm{~mL}$ of release medium (PBS, $\mathrm{pH} 7.4$ ). Samples were stored at $37{ }^{\circ} \mathrm{C}$ in a water bath. At predetermined time points, a sample was taken from medium above the gel, the amount of NR released from the gel was quantified and cumulative release was calculated. At this point, there was no separation step as only a low percentage of NR was released (i.e. $20 \%$ released after $72 \mathrm{~h}$ ). For the NR quantification, aliquots of release samples were diluted with PBS and analysed using a plate reader SPARK ${ }^{\circledR} 10 \mathrm{M}$, Tecan at 553/636 $\mathrm{nm}$ excitation/emission wavelengths.

\subsubsection{The evaluation of NC integrity}

The process of gel formation involved gelator solubilisation at elevated temperature which can impact NC properties, thus their integrity was assessed. This was done by heating, both, NCs dispersion and gel-NC composite to $60^{\circ} \mathrm{C}$. At this temperature, the gelator is expected to dissolve, liberating the NCs. A sample was collected before the gel restructured, and NC size was determined as described above (2.2.1).

\subsubsection{Injectability of the gel nanocomposite}

Evaluation of gel reformation after injection involved dissolution of the gelator in NR HA $80 \mathrm{~nm}$ NCs at 60 ${ }^{\circ} \mathrm{C}$. While still in liquid form, the formulation was then loaded into a syringe and allowed to cool to RT ( 30 $\mathrm{min})$. When the gel had formed, the syringe contents were dispensed through a needle ( $25 \mathrm{G})$ into a vial.

\section{Results and discussion}

220 The objective of this work was to develop a novel injectable composite intended for intratumoural delivery of anti-cancer drugs. The composite consist of HA NCs dispersed in a LMWG. The production and characterization of the NCs, the gel and the resulting composite is discussed as follows.

\subsection{Production of HA and PGA NCs}

HA or PGA NCs were produced by self-emulsification, without the use of any solvents. Considering the first objective of this work, to reduce their size below $100 \mathrm{~nm}$, the influence of the amount of oil (Miglyol 8 812N), and the amount of surfactants (Tween ${ }^{\circledR} 80$ and Kolliphor ${ }^{\circledR}$ HS 15) was investigated as described in the supplementary information (ESI-S1). The excipients and physico-chemical characteristics of HA and PGA NCs of two sizes (i.e. 40 and $80 \mathrm{~nm}$ ) and loaded with GEM-C14 are given in Table 1. All formulations exhibited low polydispersity (PDI $\leq 0.2$ ). The charge of the NCs depended on the polymer coating with zeta potential values closer to neutral when PGA was used $(-10$ to $-4 \mathrm{mV})$ while more negative charge was observed for HA NCs (-19 to $-9 \mathrm{mV}$ ). Our lab has previously reported the preparation of polymeric NCs 
(Protamine) with a size close to $200 \mathrm{~nm}$, using a self-emulsifying technique (Jakubiak et al., 2017), however, here we describe for the first time the production of HA and PGA NCs below $100 \mathrm{~nm}$ using a selfemulsification process. The formation of nanoemulsions with a globule size $<100 \mathrm{~nm}$, first at elevated temperatures $\left(85^{\circ} \mathrm{C}\right.$ ) (Heurtault et al., 2003) and later at $30^{\circ} \mathrm{C}$ has also been reported (Lefebvre et al., 2017; Saberi et al., 2013). However, these emulsions did not have a polymer shell as those reported in this work.

A high encapsulation efficiency (>90\%) of GEM C14 is obtained in all formulations indicating compatibility between the drug and the core of NCs. High encapsulation efficiency (> 70\%) of lipophilic compounds is a characteristic for NCs (Mora-Huertas et al., 2010) and our report is in accordance with other self-emulsifying NCs (Jakubiak et al., 2017).The size and spherical shape of the NCs were additionally confirmed by TEM imaging (see ESI-Figure S2).

The drug loading $(0.1 \mathrm{w} / \mathrm{w})$ is sufficient for intra-tumoural delivery as will be illustrated by comparison to the closest literature example of Lee et al. These authors demonstrated that a polymeric film designed for treatment of gastrointestinal cancer contained $150 \mu \mathrm{g}$ of GEM per implant and showed appropriate loading as it induced complete regression of CT-26 colon carcinoma s.c. model in mice (Lee et al., 2012). With a drug loading of $0.1 \%(\mathrm{w} / \mathrm{w}$ ) or $80 \mu \mathrm{g} / \mathrm{mL}$ of GEM C14 (assuming $8 \% \mathrm{w} / \mathrm{w}$ oil/surfactant in the nanoemulsion) we can achieve $16 \mu \mathrm{g}$ per tumour (max volume that can be injected is typically $200 \mu \mathrm{l}$ ). This drug loading could potentially be sufficient for GEM C14 as compared to GEM as the lipophilic derivative will have increased retention at the administration site and also has nanomolar potency as demonstrated below (see Figure 3).

Table 1 Excipients and Physico-chemical characteristics of different NCs loaded with GEM C14 (0.1\% w/w). Mean values $(n=3)$ are shown, error bars represent standard deviation of the mean, where $n$ is number of independent trials. All NC formulations contained $0.25 \mathrm{mg}$ CTAB The aqueous phase:oil phase ratio was 1:8 (w:w). All amounts are expressed in $\mathrm{mg}$ per formulation, where final formulation volume is $1.5 \mathrm{ml}$.

HA 80 nm NCs represent hyaluronic acid coated NCs with a diameter of $80 \mathrm{~nm}$; whilst PGA 80 nm NCs are poly-Lglutamic acid coated NCs with a diameter of $80 \mathrm{~nm} ; \mathbf{H A} \mathbf{4 0} \mathbf{~ n m ~ N C s}$ are hyaluronic acid coated NCs with a diameter $40 \mathrm{~nm}$; and PGA $40 \mathrm{~nm}$ NCs are poly-L-glutamic acid coated NCs with a diameter of $40 \mathrm{~nm}$.

\begin{tabular}{|c|c|c|c|c|c|c|c|c|}
\hline \multirow[b]{2}{*}{$\begin{array}{l}\text { Formulation } \\
\text { name }\end{array}$} & \multicolumn{4}{|c|}{ NC Excipients } & \multicolumn{4}{|c|}{ NC characterisation } \\
\hline & $\begin{array}{l}\text { Kolliphor }{ }^{\circledR} \\
\text { HS } 15(\mathrm{mg})\end{array}$ & $\begin{array}{l}\text { Tween® } \\
80(\mathrm{mg})\end{array}$ & $\begin{array}{l}\text { Miglyol® } \\
812 \mathrm{~N}(\mathrm{mg})\end{array}$ & $\begin{array}{l}\text { HA or } \\
\text { PGA } \\
(\mathrm{mg} / \mathrm{ml})\end{array}$ & $\begin{array}{l}\text { Size } \\
(\mathrm{nm})\end{array}$ & PDI & $\begin{array}{l}\mathrm{ZP} \\
(\mathrm{mV})\end{array}$ & EE (\%) \\
\hline HA $80 \mathrm{~nm}$ NCs & 45 & 45 & 70 & 2 & $79 \pm 6$ & 0.2 & $-19 \pm 1$ & $95 \pm 8$ \\
\hline PGA $80 \mathrm{~nm}$ NCs & 45 & 45 & 70 & 2 & $79 \pm 5$ & 0.2 & $-10 \pm 1$ & $90 \pm 5$ \\
\hline HA $40 \mathrm{~nm} N C s$ & 53 & 53 & 53 & 2 & $40 \pm 2$ & 0.2 & $-9 \pm 1$ & $92 \pm 7$ \\
\hline PGA $40 \mathrm{~nm}$ NCs & 53 & 53 & 53 & 2 & $34 \pm 2$ & 0.1 & $-4 \pm 1$ & $90 \pm 5$ \\
\hline
\end{tabular}


The importance of the NCs formulations developed herein is reflected by the known influence of the physicochemical properties of nanocarriers on their diffusion through the tumour stroma (Gratton et al., 2008; Ernsting et al., 2013). (Lee et al., 2010; Jiang et al., 2008). Generally, smaller particles i.e. $\leq 100 \mathrm{~nm}$ perform better in terms of accumulation and distribution in tumours (Chauhan et al., 2012; Saw et al., 2018;

265 Cabral et al., 2011; Meerovich et al., 2008). Moreover, in a recent publication by our group, PGA-PEG NCs of $100 \mathrm{~nm}$ were found to be drained into lymph nodes faster than the $200 \mathrm{~nm}$ NCs of the same composition (Abellan-Pose et al., 2016). Although the majority of the work in the literature describes the intravenous administration of nanoparticles, intratumoural injection (the intended application of our nanocomposite hydrogel) of small NCs locally also has the potential to give increased penetration through the tumour as 270 described for Pegylated gold nanoparticles (50 nm), an emulsion (85 nm) and neutral liposomes (120 nm). Whilst an $250 \mathrm{~nm}$ emulsion and $100 \mathrm{~nm}$ liposomes with positive surface charge had limited diffusion (Laprise-Pelletier et al., 2018; Nomura et al., 1998).

\subsubsection{In vitro release of GEM C14 from NCs}

We progressed to the release studies of GEM C14 without undertaking drug stability studies as very similar 275 alkanoyl gemcitabine derivatives were previously established as being stable in vitro (Immordino et al., 2004) . In addition, for other $\mathrm{N}$-alkanoyl gemcitabine derivatives the amide linkage was also demonstrated to be stable between 6 and 8 in vitro (Wickremsinhe et al., 2013; Bender et al., 2009). The release studies were carried out under sink conditions, by incubating the NCs in PBS at $37^{\circ} \mathrm{C}$ for 1 month. The amount released from HA 40 and $\mathrm{HA} 80 \mathrm{~nm}$ was evaluated by analysis of the amount remaining in the NCs and then subtracting this from the initial amount encapsulated. Both formulations showed a similar biphasic drug release profile (Fig. 1), characterised by an initial burst release of $\sim 20 \%$ followed by a second phase in which further $\sim 40 \%$ of drug was released over 1 month. The initial burst release maybe attributed to the non-ionic surfactants solubilising drug at the oil water interface (Youm et al., 2014). The total amount of GEM C14 released from the NCs after one month was $63 \pm 8$ and $66 \pm 10 \%$ from HA 40 and HA 80 nm NCs respectively. The amount of drug that remained encapsulated in NCs during the release studies is notable ( 35\% after 1 month) thus showing its stability inside the nanocarrier and the ability of the nanocarrier to maintain sustained release. Similarly, Bastiancich et al. reported $56 \%$ of lauroyl-gemcitabine (GEM C12) released in the first $48 \mathrm{~h}$ and 77\% released after 1 month (Bastiancich et al., 2016). Delayed release of GEM C14 (with a longer carbon chain compared to C12) can be attributed to its higher affinity towards the oil core and the diffusion between the hydrophobic core and surrounding environment can be hindered by the packing density of the surfactant molecules and the presence of the polymer coating (Lamprecht et al., 2002; Poletto et al., 2008). These data suggest the potential for sustained release in future in vivo studies. 


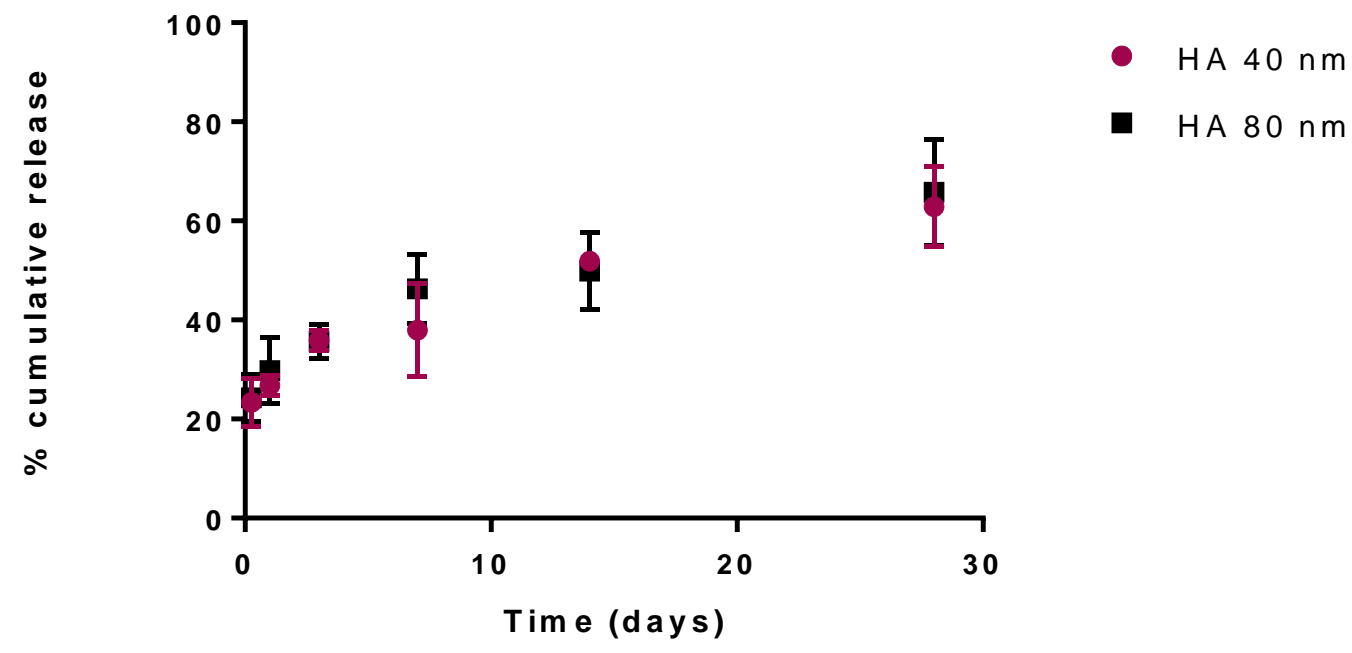

295 Figure 1 Release profile of GEM C14 from HA 80 and HA 40 NCs with a drug loading of 0.1\%. Volume of NCs formulation used was $0.5 \mathrm{~mL}$ with $37.5 \mathrm{~mL}$ of PBS $(\mathrm{pH}=7.4)$. Experiments were performed at $37^{\circ} \mathrm{C}$. Mean values are shown; error bars represent standard deviations of 3 independent trials.

\subsubsection{Stability of NCs upon storage and after incubation in bio-relevant media}

From an industrial and translational perspective, it is important to obtain formulations that are stable upon storage. Additionally, a critical aspect of physiological relevance is their stability in bio-relevant media as it is known that stability in biological media can be a barrier in the development of many nanoformulations (Moore et al., 2015). Therefore, storage stability at RT and in the fridge as well as the stability of the NCs in PBS, $\mathrm{pH}=7.4$ and in RPMI cell culture medium was investigated.

In the stability study, neither aggregation nor precipitation of nanoparticles were observed during storage $\leq$ 1 month. This good colloidal stability profile, which could be attributed to the electrostatic repulsion between the negatively charged NCs agrees with the stability data reported for other polymeric based NCs (Lozano et al., 2013; González-Aramundiz et al., 2015; Zanotto-Filho et al., 2013; Abellan-Pose et al., 2016). Although, changes in particle size of the nanoparticles throughout the entire course of the study were minimal, PGA NCs exhibited significant (1-way ANOVA Dunnett's multiple comparison test, $p<0.05$ ) increase in size after 4 weeks storage for both PGA 40 and $80 \mathrm{~nm}$ NCs. This could be the result of film thinning and NCs coalescence due to the lower polymer coverage (assessed by ZP) which led to weak repulsive forces between PGA NCs compared to HA NCs. 
A)

HA $80 \mathrm{~nm}$

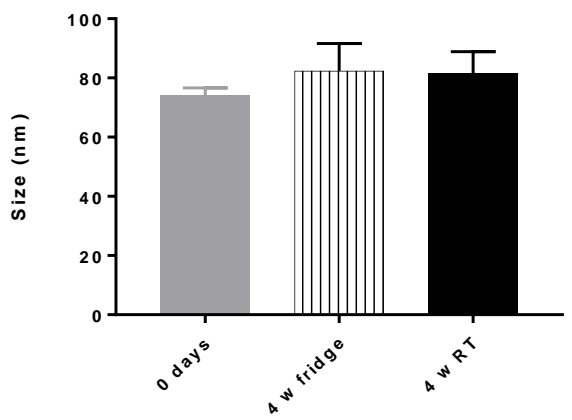

B)

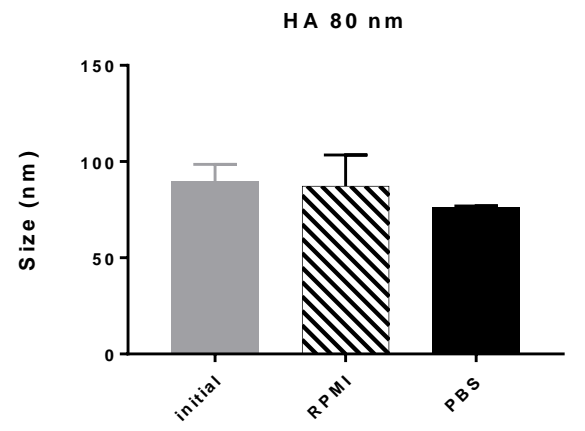

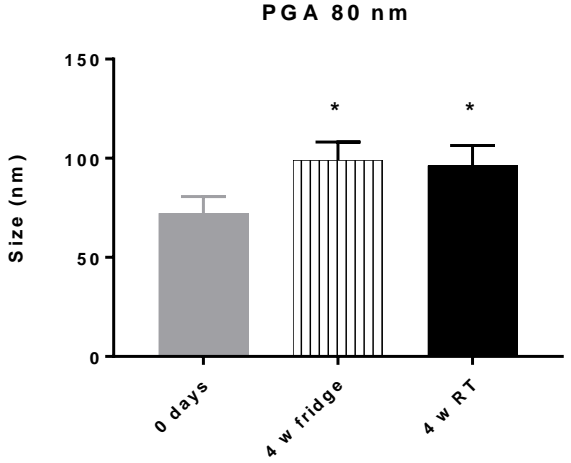

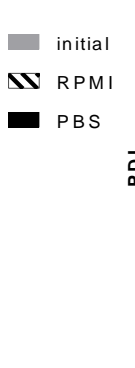

HA $80 \mathrm{~nm}$

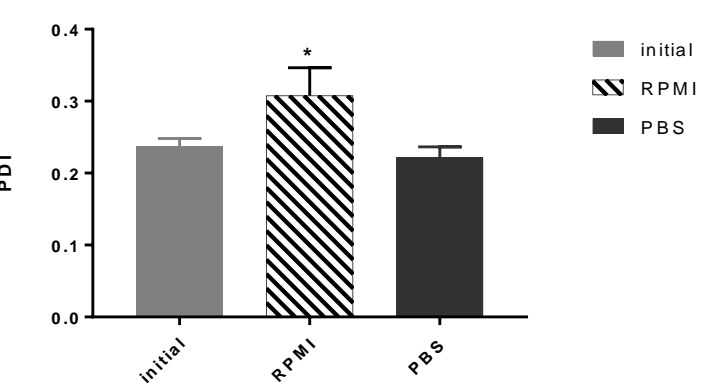

Figure 2 A) Influence of the storage conditions (room or fridge temperature) on the size of NCs after 4 weeks. Diameters of HA 80 and PGA $80 \mathrm{NCs}$ are presented after storage in a cupboard at RT or in the fridge at $8{ }^{\circ} \mathrm{C}$. B) Physico-chemical characteristics (diameter and PDI) of HA $80 \mathrm{~nm} N C s$ after incubation with PBS and RPMI medium. Measurements were performed on the day of the incubation at RT. Mean values are shown; error bars represent standard deviations of 3 independent trials. 1 way ANOVA Dunnett's multiple comparison test, diameter of NCs was compared with initial size, $*(p<0.05)$.

The size of HA $80 \mathrm{~nm}$ NCs did not change significantly after incubation in PBS nor in RPMI. However, a slight increase in the PDI value $(p<0.05$, Dunnett's multiple comparison test) was observed upon incubation of the NCs in RPMI medium. This could be a consequence of higher salt content (2x potassium ions) in the RPMI medium and is more likely due to the potential interaction of the proteins from the FBS serum in the RPMI, with the NCs. The presence of polymers and other molecules on the surface of particles is a well-known approach for conferring electrostatic and steric stabilisation to NCs (Tan et al., 2010; Storm et al., 1995; Moore et al., 2015).

\subsubsection{In vitro activity of GEM C14 loaded polymeric NCs in cancer cells}

Human colorectal and pancreatic carcinoma cells were exposed to serial dilutions of NCs (blank or loaded with the drug) and to drug alone for $72 \mathrm{~h}$. Subsequently, MTT assays were carried out to assess cell viability and $\mathrm{Gl}_{50}$ values are presented in Figure 3. GEM C14-loaded NCs as well as free drugs (GEM-HCl and GEM C14) gave nanomolar $\mathrm{Gl}_{50}$ values in all wild type cancer cell lines (HCT 116, MIA PaCa-2 and Panc1), demonstrating high potency. On the other hand, blank NCs (no drug) exhibited a 10 to 100 -fold higher 
$\mathrm{Gl}_{50}$ values than drug containing NCs implying that growth inhibition of these cancer cells is mainly due to the drugs activity. Representative dose response curves are shown in ESI-Figure S6 for HCT 116 and MIA PaCa-2 cell lines and Figure S7 for Panc-1 and GEM resistant Panc-1 cell lines.
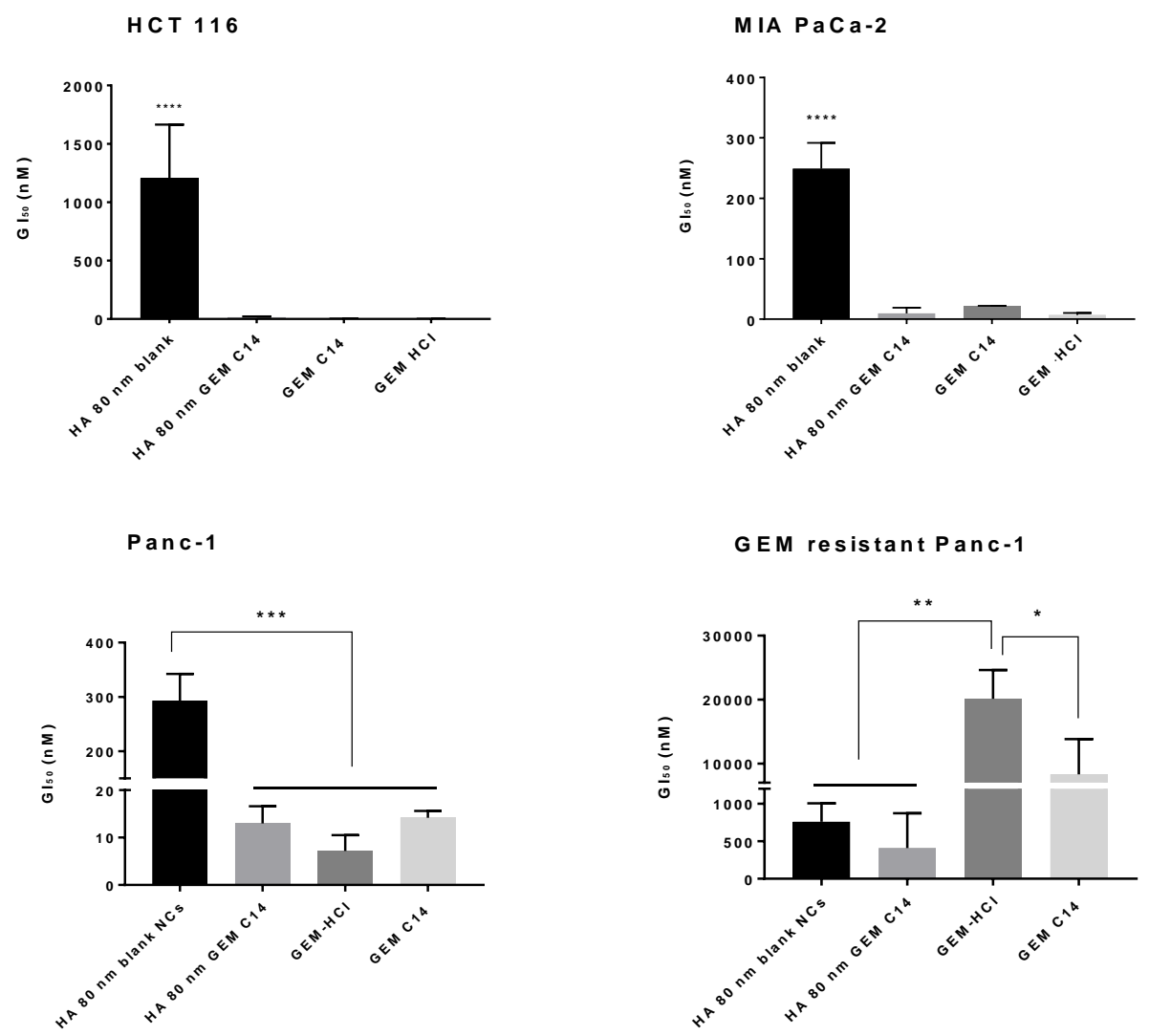

Figure 3 Mean Gl 50 values (nM) \pm s.d. in HCT 116, MIA PaCa-2, Panc-1 and GEM resistant Panc-1 cell lines following $72 \mathrm{~h}$ treatment, with HA $80 \mathrm{~nm}$ NCs blank or loaded with GEM C14 and for naked drugs: GEM-HCl or GEM C14. Oneway ANOVA multiple comparisons test ${ }^{* * * *}(p<0.0001) ;{ }^{* * *}(p<0.001) ;{ }^{* *}(p<0.01) ;{ }^{*}(p<0.05)$. Mean values are shown; error bars represent standard deviations of 3 independent trials.

A pancreatic GEM-resistant cell line (GEM R Panc-1) was obtained by continuous culture of parental Panc1 cells in gemcitabine and maintained with gemcitabine at a dose of $1 \mu \mathrm{M}$. In this cell line, free drug in the form of either GEM C14 or GEM-HCl exhibited negligible growth inhibitory effects with $\mathrm{Gl}_{50}$ values in the $\mu \mathrm{M}$ range confirming its resistance towards not only commercial GEM-HCl but also towards the modified lipophilic GEM C14. Activity of GEM C14 loaded NCs in GEM resistant Panc-1 cell line showed 20 to 50 times lower $\mathrm{Gl}_{50}$ values compared to those of GEM C14 and GEM-HCl respectively. Interestingly, in contrast to data on wild type cancer cell lines, blank NCs in GEM resistant Panc-1 cell line showed similar activity to drug loaded NCs. For this drug resistant cell line, growth inhibition appears to be a consequence of the $\mathrm{NC}$ formulation which includes both non-ionic surfactants and a small amount of a cationic surfactant i.e CTAB. CTAB has been described as a cytotoxic agent (He et al., 2011; Ito et al., 2009). The presence of 
CTAB in blank NCs may possibly explain the similar toxicity of empty and loaded NCs on the GEM R pancreatic cell line.

\subsection{Association of polymeric NCs and LMWGs}

N4-octanoyl-2'-deoxycytidine was chosen as a gelator on account of the absence of solvents used in its formulation, thus its compatibility with NCs. Initially, hydrogels consisting of only gelator and water were rapidly formed after a heating-cooling cycle. The storage modulus ( $\left.G^{\prime}\right)$ derived from the LVE region of amplitude sweep tests was used as a measure of gel strength (Fig. S3). Results indicated that the concentration of gelator can influence gel strength in the hydrogel only and in nanocomposite hydrogels with NCs (Figure 4). For pure hydrogels, G' values increased from $148 \mathrm{~Pa}$ to $1760 \mathrm{~Pa}$ in gelator concentration range between 0.5 and $2 \% \mathrm{w} / \mathrm{v}$. However, for the highest concentration $(2.5 \% \mathrm{w} / \mathrm{v})$, the value of the elastic modulus dropped to $517 \mathrm{~Pa}$. The influence of the gelator concentration on the value of the elastic modulus has been reported elsewhere (Friggeri et al., 2004; Frith et al., 2015). With increases in gelator concentration the elastic modulus will increase until it reaches a plateau (Mohmeyer and Schmidt, 2005) or a decrease in G' values can be observed above certain concentrations. At higher concentrations the gelation process can almost be instantaneous resulting in shorter fibers and consequently reduced elasticity of the system or can lead to precipitation and the disruption of the gelator network (Menger and Caran, 2000). In the case of gel-NCs composite, it is important to note that the gelator, N4-octanoyl-2'deoxycytidine, at a concentration of $0.5 \% \mathrm{w} / \mathrm{v}$ failed to gel in the presence of NCs. Whereas with $1 \% \mathrm{w} / \mathrm{v}$ gelator concentration a gel was macroscopically formed but with a short LVE region. However, further increases in gelator concentration improved the linearity of the LVE region and resulted in increased gel strength (Fig. S3 B). When pure hydrogel and gel-NCs composite are compared at the same gelator concentration (2.5\% w/v) a 10 -fold increase in G' values in the presence of NCs is noted. Additionally, gel strength was independent of NCs' size $(40$ or $80 \mathrm{~nm}$ ) or polymeric coating (hyaluronic acid or poly-glutamic acid) as their G' were not significantly different (ESI-S4).

375 As we have seen, the presence of NCs limits the ability of gel formation below certain gelator concentrations which implies that the amount of NCs can also play an important role in optimal LMWG-NCs composite formulation. Figure 4 shows that a higher amount of NCs ( 8 vs 2 and $4 \%$ ) decreases the elastic modulus of the nanocomposite gel formulations regardless of the gelator concentration. Unlike polymeric gels, the N4-octanoyl-2'-deoxycytidine LMW gelator is a small molecule which in the presence of polymeric NCs hypothetically can participate in oil-water interface of lipid NCs due to its amphiphilic structure. As the amount of NCs increases, the number of gelator molecules at the oil/water interface can also potentially increase and subsequently decrease the gelator involvement in the formation of gel network resulting in the formation of a gel with a weaker structure. These data are of high importance as it is the first time that nanocomposite formulation of a LMWG and polymeric NCs has been evaluated; only composites of LMWG and inorganic and metal particles have been previously reported (Ghosh et al., 2017; Mitra and Das, 2008; Nanda et al., 2012; Song et al., 2010). Recently Ghosh et al. have showed that a hydrogel comprised of 
hydroxyapatite (HAP), fluorenyl-9-methoxycarbonyl diphenylalanine (FmocFF) and Fmoc-arginine (which does not gel but mediates high affinity to HAP) gave novel hydrogels with mechanical strength greater than the gel alone appropriate for bone regeneration ie. $29 \mathrm{KPa}$. Whereas decreases in elastic moduli were reported by (Nanda et al., 2012), where thiol (-SH) containing amino acid/peptide ligands have been used to stabilize small silver nanoparticles, and then they were incorporated into a N-terminally Boc (tertbutyloxycarbonyl) group-protected tripeptide (Boc-Phe-Phe-Ala-OH). In this paper the concentration the nanoparticles was an important parameter and their proposed model was that the interaction of the functional group on the surface interferes with gelator self-assembly and weakens the gel. However in the nancomposite gel our proposed model is that there is hydrogen bonding between the nanocapsule polymer shell and the pentose sugar exposed on the external surface of fiber (as demonstrated in a previous paper from our group (Angelerou et al., 2018)) that binds the nanofibers together.

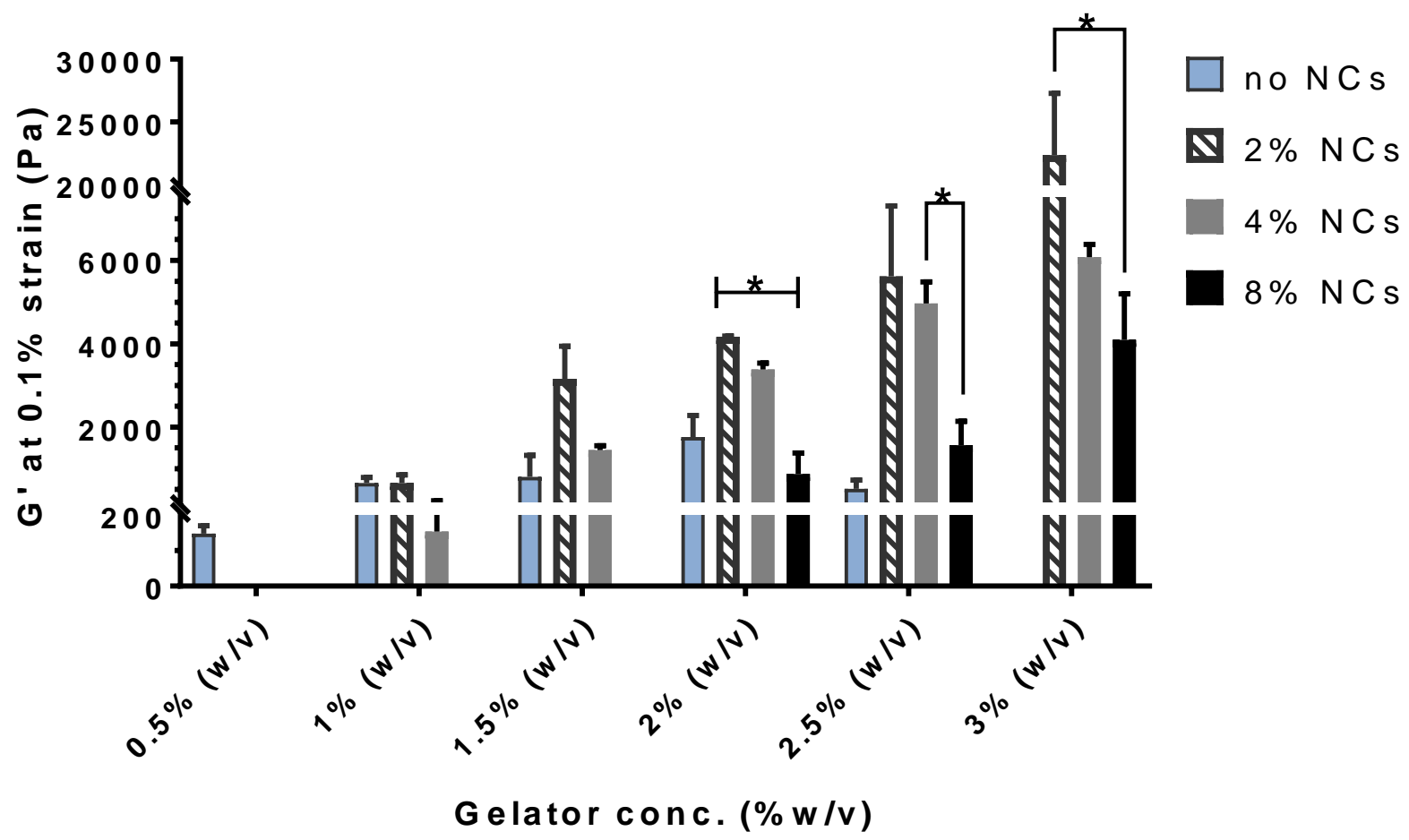

Figure 4 Influence of concentration of NCs (2, 4 and $8 \% \mathrm{w} / \mathrm{V})$ on gel strength (G') in gel-HA $80 \mathrm{~nm}$ NCs systems. The effect is compared among various gelator concentrations: 1, 1.5, 2, 2.5, 3\% w/v. Tests were performed a day after gel preparation at $37{ }^{\circ} \mathrm{C}, y=0.05-100 \%$ and $\left.\omega=10 \mathrm{rad} / \mathrm{s}\right)$. Mean values are shown; error bars represent standard deviations of 3 independent trials. 1 way ANOVA Tukey's multiple comparisons test with * $(p<0.05)$. 


\subsubsection{In vitro controlled release of NCs from the gel}

Finally release of NCs from gel composite was assessed. For this experiment, NR was loaded into the NCs as this hydrophobic compound has high affinity towards the oil core as shown in the ESI-Figure S8 with $\sim 80 \%$ retained in the NC after $72 \mathrm{~h}$. Initially a ratio of gel to release medium of 1:5 (v:v) was chosen after reviewing release conditions from NCs and gel formulations (Appel et al., 2015; Bastiancich et al., 2016; Bunzen and Kolehmainen, 2013). However, this volume of buffer was found to be too low for the release assessment from gels, since the whole release medium gelled after $24 \mathrm{~h}$. This can be explained by gel disassembly in contact with water and reassembly of fibers once the gelator was distributed in the medium. Therefore, $12.5 \mathrm{~mL}$ was added to $2 \% \mathrm{w} / \mathrm{v}$ gel prepared in $0.5 \mathrm{~mL}$ NCs and no gelling of the medium occurred. Hence these conditions were used for further release experiments. Although, different sizes of NCs and different amounts of NCs were compared (Figure 5) release plots show similar profiles. The gel containing $8 \%$ NCs released NR slightly quicker than the gel with $4 \%$ NCs. These data are in accordance with gel strength. Nanocomposite gels formed with fewer NCs (4\%) demonstrated higher G' values and retained NCs longer in the composite, compared to formulation containing $8 \% \mathrm{NCs}$. Although not significant, gels containing $80 \mathrm{~nm} \mathrm{NCs} \mathrm{showed} \mathrm{faster} \mathrm{release} \mathrm{of} \mathrm{NR-loaded} \mathrm{NCs} \mathrm{than} \mathrm{gels} \mathrm{containing} \mathrm{smaller} 40 \mathrm{~nm}$ NCs. Similar observations were reported for lipid NCs where GEM C12 plays the role of gelator where NCs of 29 and $55 \mathrm{~nm}$ showed negligible difference (10-20\%) in release from their gel (Moysan et al., 2014). \% released decreases at $72 \mathrm{~h}$ as there is some partitioning of the NR into the release medium.

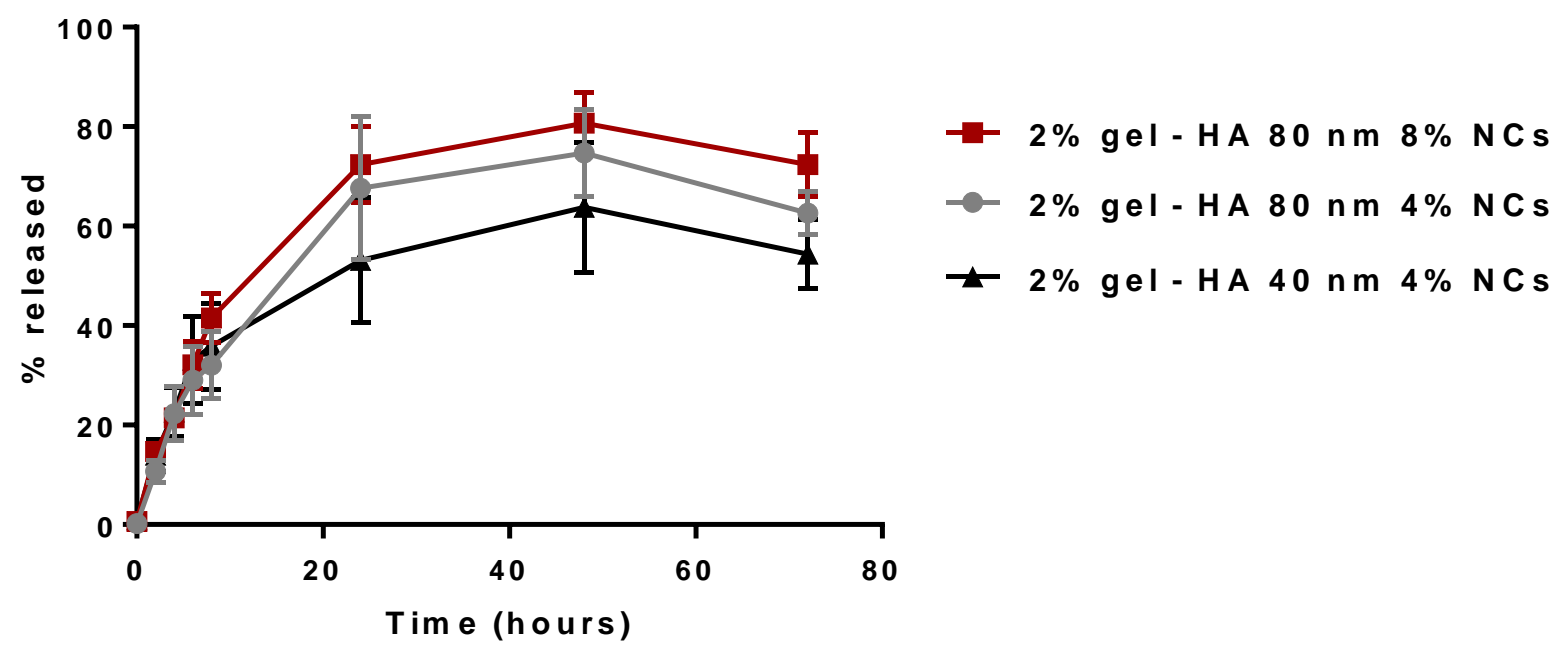

Figure 5 Cumulative release of NR-loaded NCs from gel-NCs formulation at $37^{\circ} \mathrm{C}$ in PBS medium, $p H=7.4$. Concentration of gelator in all systems is $2 \% \mathrm{~W} / \mathrm{v}$ and NCs used in this experiment are: HA $80 \mathrm{~nm} N C s$ of 4 and $8 \% \mathrm{~W} / \mathrm{V}$ 
Following the release of NCs from the gel, the size of NCs released in the medium was examined. Released NCs of $172 \pm 24 \mathrm{~nm}$ were observed, which is larger than the initial size of NCs ( $80 \mathrm{~nm})$. Hence the integrity of NCs was evaluated under conditions of gel preparation. In Figure 6 , the size of NCs in the presence or absence of gelator after heating at $60^{\circ} \mathrm{C}$ is presented. NCs heated to $60^{\circ} \mathrm{C}$ exhibited only a slight increase in size to $55 \pm 3$ and $98 \pm 17 \mathrm{~nm}$ for HA 40 and HA $80 \mathrm{~nm}$ formulations respectively. However, in the presence of gelator, the size of NC for both systems, increased up to $\sim 200 \mathrm{~nm}$. It seems that it is not the temperature that causes increase in size of NCs, but the presence of gelator around NCs. PDI values for all samples were $\leq 0.2$ suggesting that no aggregation occurred. How much this increase in size would limit the diffusion in the tumour mass is difficult to predict. There is limited data in the literature describing the diffusion of nanoparticles across the tumour. These data indicate that nanoparticles with a size of $250 \mathrm{~nm}$ or a positive surface charge may have a limited diffusion(Laprise-Pelletier et al., 2018; Nomura et al., 1998). According to this, the NCs described in the manuscript are expected to have adequate diffusion across the tumour.

Irrespective of the size observed by light scattering, using TEM imaging it was possible to confirm the presence of $\mathrm{NCs}<100 \mathrm{~nm}$ diameter, dispersed in the gel (Figure 6B). The presence of fibrous network is clearly seen with homogenous distribution of spheroid particles in between fibers. Therefore, it could be inferred that the increase in size observed by light scattering is not due to the aggregation of the NCs but rather associated to the presence of fibers around the NCs.

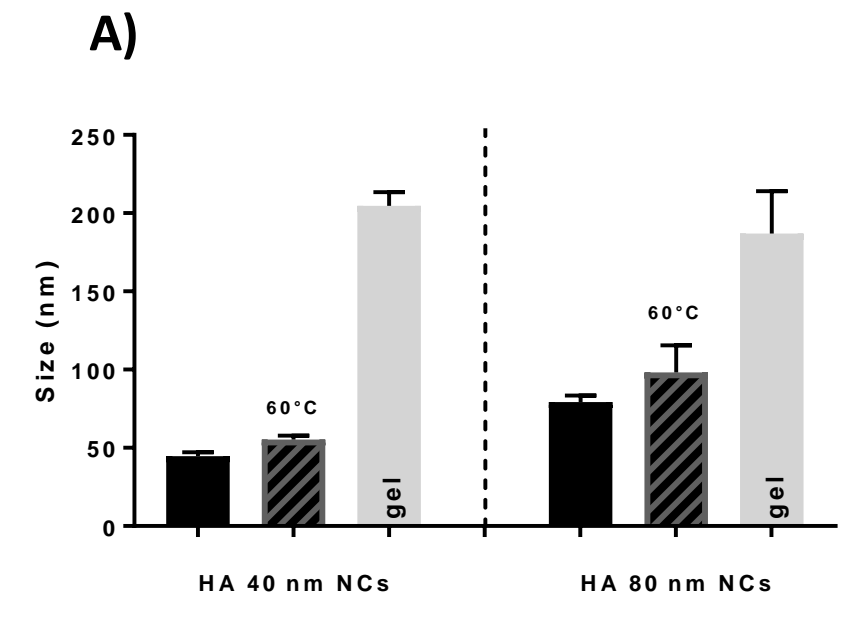

B)

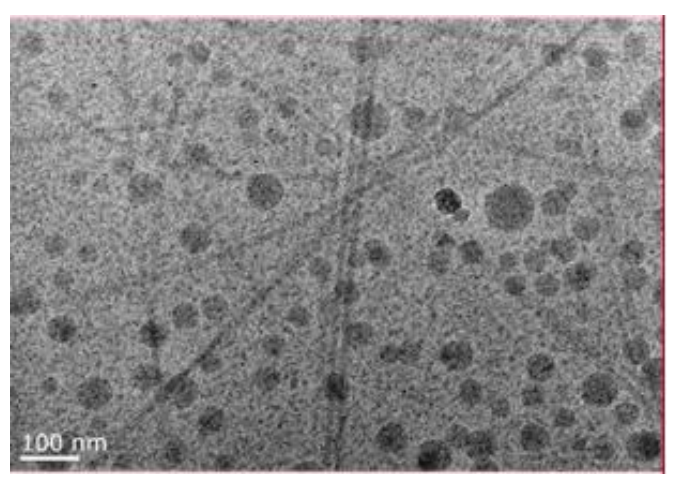

Figure 6 A) Change of initial size of HA 40 or HA $80 \mathrm{~nm}$ NCs after being exposed to heat at $60-70{ }^{\circ} \mathrm{C}$ with and without gelator. Black bars present size of NCs alone before the heating, black bars with grey lines NCs alone after the heating 
at $60{ }^{\circ} \mathrm{C}$ and grey lines NCs in presence of solubilised gelator after the heating to $60{ }^{\circ} \mathrm{C}$. Mean values are shown; error bars represent standard deviations of 3 independent trials. B) cryo-TEM imaging of $2 \% \mathrm{w} / \mathrm{v}$ gelator $-8 \% \mathrm{w} / \mathrm{v} H \mathrm{H} 80$ $n m$ NCs.

\subsubsection{Injectability}

When considering a formulation for direct intra-tumoural delivery, injectability of the system is a crucial characteristic to evaluate. Our group has previously reported $70 \%$ gel recovery, after a time-dependent rheology test, for the N4-octanoyl-2'-deoxycytidine. In Figure 7, an image of a syringe loaded with gel-NCs composite formulation, and the appearance after its contents were dispensed through the needle is shown. The gel formulation with NCs reformed instantly and remained in its gel form. The vial has been inverted to show that the gel has retained its viscoelastic properties after passing through the needle. Furthermore, their ability to be placed in tissue was tested in an in vitro simulation of intra-tumoural delivery i.e. chicken thigh. To mimic a resection site and intra-tumoural delivery, we bored out a hole in chicken thigh and used a syringe (without needle) to place the gel inside and observed the shape of the gel. Formulations with the same gelator concentration ( $2 \% \mathrm{w} / \mathrm{v}$ ) and different amounts of $\mathrm{NCs}$ ( 8 and $4 \% \mathrm{w} / \mathrm{v}$ ) were compared in terms of injectability. While the gel containing $4 \% \mathrm{w} / \mathrm{v}$ NCs retained its structure, the gel containing $8 \% \mathrm{w} / \mathrm{v} \mathrm{NCs}$ did not reform after dispensing through a syringe (images in ES1- S5).
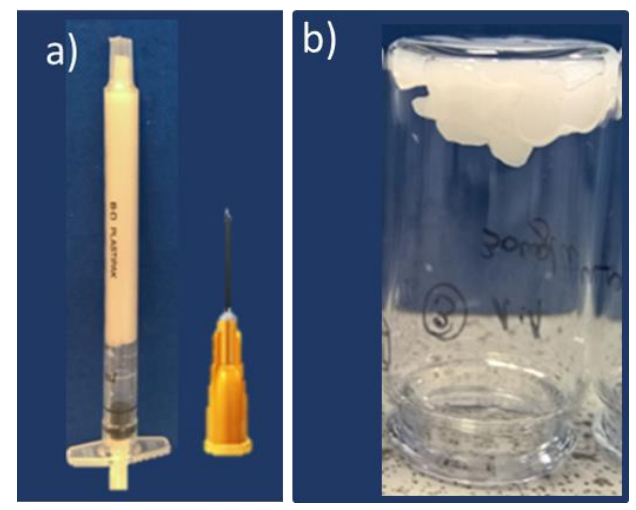

Figure $7 \mathrm{Gel}$ formulation ( $3 \% \mathrm{w} / \mathrm{v}$ gel- $4 \% \mathrm{HA} 80 \mathrm{~nm}$ NCs systems) loaded in a syringe (a) and dispensed through the syringe using needle (25G) into the vial (b).

Several LMWG formulations and gel-nanoparticle composites (Chaudhari et al., 2015; Appel et al., 2012) have shown the ability to recover near-total initial strength. We have observed here that gel structure is not compromised after injection of the nanocomposite hydrogel formulation and this is of significant importance for future in vivo experiments.

\section{Conclusions}

A novel nanocomposite formulation, consisting of an in-situ forming hydrogel containing polymeric NCs, has been developed. The hydrogel, here described for the first time, is made of a low molecular weight gelator (N4-octanoyl-2'-deoxycytidine) and has been shown able to accommodate a significant amount of NCs within its fibrillar structure. The NCs, produced by a self-emulsification technique, were a very small 
size (40-150 nm) and provided a controlled release of the drug encapsulated for more than one month. Specific features of this nanocomposite formulation include (i) adequate mechanical strength; (ii) capacity to control the released of the nanocapsules; and (iii) ability to gel in situ upon injection. This formulation could have potential for intratumoural delivery of anticancer drugs in the case of unresectable cancers such as gastric, pancreatic or oesophageal cancer. This delivery technology could also be of interest as a long acting injectable for subcutaneous or intra-cavital administration.

Acknowledgments:

Authors acknowledge as well the assistance provided by Mike Fay and Christopher Parmenter in Nottingham Nanotechnology and Nanoscience Centre for TEM imaging. Secondly, special thanks to Kathryn Skilling for synthesis of compounds N4-myristoyl gemcitabine and N4-octanoyl-2'-deoxycytidine.

Funding: This work was supported by the European Commission, Education, Audiovisual and Culture Executive Agency (EACEA), Erasmus Mundus programme, NanoFar doctorate funding.

\section{References}

Abellan-Pose, R., Teijeiro-Valiño, C., Santander-Ortega, M.J., Borrajo, E., Vidal, A., Garcia-Fuentes, M., Csaba, N., Alonso, M.J., 2016. Polyaminoacid Nanocapsules for Drug Delivery to the Lymphatic System: Effect of the Particle Size. Int. J. Pharm. 509, 107-117. https://doi.org/10.1016/j.ijpharm.2016.05.034

Angelerou, M.G.F., Frederix, P.W.J.M., Wallace, M., Yang, B., Rodger, A., Adams, D.J., Marlow, M., Zelzer, M., 2018. Supramolecular Nucleoside-Based Gel: Molecular Dynamics Simulation and Characterization of Its Nanoarchitecture and Self-Assembly Mechanism. Langmuir 34, 6912-6921. https://doi.org/10.1021/acs.langmuir.8b00646

Appel, E.A., del Barrio, J., Loh, X.J., Scherman, O.A., 2012. Supramolecular polymeric hydrogels. Chem. Soc. Rev. 41, 6195-6214. https://doi.org/10.1039/c2cs35264h

Appel, E.A., Tibbitt, M.W., Webber, M.J., Mattix, B.A., Veiseh, O., Langer, R., 2015. Self-assembled hydrogels utilizing polymer-nanoparticle interactions. Nat. Commun. 6, 1-9. https://doi.org/10.1038/ncomms7295

Bastiancich, C., Vanvarenberg, K., Ucakar, B., Pitorre, M., Bastiat, G., Lagarce, F., Préat, V., Danhier, F., 2016. Lauroylgemcitabine-loaded lipid nanocapsule hydrogel for the treatment of glioblastoma. J. Control. Release 225, 283293. https://doi.org/10.1016/j.jconrel.2016.01.054

Bender, D.M.., Bao, J.., Dantzig, A.H.., Diseroad, D.W., Law, K.L.., Magnus, N.A.., Peterson, J.A.., Perkins, E.J.., Pu, Y.J.., Reutzel-Edens, S.M.., Remick, D.M.., Starling, J.J.., Stephenson, G.A.., Vaid, R.K.., Zhang, D.., McCarthy, J.R., 2009. Synthesis, Crystallization, and Biological Evaluation of an Orally Active Prodrug of Gemcitabine. J. Med. Chem. 52, 6958-6961.

Borrajo, E., Abellan-Pose, R., Soto, A., Garcia-Fuentes, M., Csaba, N., Alonso, M.J., Vidal, A., 2016. Docetaxel-loaded Polyglutamic acid-PEG Nanocapsules for the Treatment of Metastatic Cancer. J. Control. Release 238, 263-271. https://doi.org/10.1016/j.jconrel.2016.07.048

Bunzen, H., Kolehmainen, E., 2013. In Situ Formation of Steroidal Supramolecular Gels Designed for Drug Release. Molecules 18, 3745-3759. https://doi.org/10.3390/molecules 18043745 
Cabral, H., Matsumoto, Y., Mizuno, K., Chen, Q., Murakami, M., Kimura, M., Terada, Y., Kano, M.R., Miyazono, K., Uesaka, M., Nishiyama, N., Kataoka, K., 2011. Accumulation of sub-100 nm polymeric micelles in poorly permeable tumours depends on size. Nat. Nanotechnol. 6, 815-823. https://doi.org/10.1038/nnano.2011.166

Chaudhari, A.K., Han, I., Tan, J., 2015. Multifunctional Supramolecular Hybrid Materials Constructed from Hierarchical Self-Ordering of In Situ Generated Metal-Organic Framework ( MOF ) Nanoparticles. Adv. Mater. 27, 4438-4446. https://doi.org/10.1002/adma.201501448

Chauhan, V.P., Stylianopoulos, T., Martin, J.D., PopoviÄ, Z., Chen, O., Kamoun, W.S., Bawendi, M.G., Fukumura, D., Jain, R.K., 2012. Normalization of tumour blood vessels improves the delivery of nanomedicines in a sizedependent manner. Nat. Nanotechnol. 7, 383-388. https://doi.org/10.1038/nnano.2012.45

Cheetham, A.G., Zhang, P., Lin, Y., Lock, L.L., Cui, H., 2013. Supramolecular Nanostructures Formed by Anticancer Drug Assembly. J. Am. Chem. Soc. 135, 2907-2910. https://doi.org/10.1021/ja3115983

Contri, R. V, Bonferoni, M.C., Caramella, C., Frank, A.G., Pohlmann, A.R., Guterres, S.S., 2014. Chitosan gel containing polymeric nanocapsules : a new formulation for vaginal drug delivery. Int. J. Nanomedicine 9, 31513161. https://doi.org/https://doi.org/10.2147//JN.S62599

Ernsting, M.J., Murakami, M., Roy, A., Li, S.-D., 2013. Factors controlling the pharmacokinetics, biodistribution and intratumoral penetration of nanoparticles. J. Control. Release 172, 782-794. https://doi.org/10.1016/j.jconrel.2013.09.013

Friggeri, A., Feringa, B.L., Van Esch, J., 2004. Entrapment and release of quinoline derivatives using a hydrogel of a low molecular weight gelator. J. Control. Release 97, 241-248. https://doi.org/10.1016/j.jconrel.2004.03.012

Frith, W.J., Donald, A.M., Adams, D.J., Aufderhorst-Roberts, A., 2015. Gels formed from amino-acid derivatives, their novel rheology as probed by bulk and particle tracking rheological methods. J. Nonnewton. Fluid Mech. 222, 104-111. https://doi.org/http://dx.doi.org/10.1016/j.jnnfm.2014.09.008

Ghosh, M., Halperin-Sternfeld, M., Grigoriants, I., Lee, J., Nam, K.T., Adler-Abramovich, L., 2017. Arginine-Presenting Peptide Hydrogels Decorated with Hydroxyapatite as Biomimetic Scaffolds for Bone Regeneration. Biomacromolecules 18, 3541-3550. https://doi.org/10.1021/acs.biomac.7b00876

González-Aramundiz, J.V., Olmedo, M.P., González-Fernández, Á., Fernández, M.J.A., Csaba, N.S., 2015. Protaminebased nanoparticles as new antigen delivery systems. Eur. J. Pharm. Biopharm. 97, 51-59. https://doi.org/10.1016/j.ejpb.2015.09.019

Gonzalez-Aramundiz, J.V., Presas, E., Dalmau-Mena, I., Martinez-Pulgarin, S., Alonso, C., Escribano, J.M., Alonso, M.J., Csaba, N.S., 2017. Rational design of protamine nanocapsules as antigen delivery carriers. J. Control. Release 245, 62-69. https://doi.org/10.1016/j.jconrel.2016.11.012

Gou, M., Li, X., Dai, M., Gong, C., Wang, X., Xie, Y., Deng, H., Chen, L., Zhao, X., Qian, Z., Wei, Y., 2008. Pharmaceutical Nanotechnology A novel injectable local hydrophobic drug delivery system: Biodegradable nanoparticles in thermo-sensitive hydrogel $\square$. Int. J. Pharm. 359, 228-233. https://doi.org/10.1016/j.jpharm.2008.03.023

555 Grant, J., Blicker, M., Allen, C., 2005. Hybrid Films from Blends of Chitosan and Egg Phosphatidylcholine for Localized Delivery of Paclitaxel. J. Pharm. Sci. 94, 1512-1527. https://doi.org/10.1002/jps.20379

Gratton, S.E. A, Ropp, P. A, Pohlhaus, P.D., Luft, J.C., Madden, V.J., Napier, M.E., DeSimone, J.M., 2008. The effect of particle design on cellular internalization pathways. Proc. Natl. Acad. Sci. U. S. A. 105, 11613-8. https://doi.org/10.1073/pnas.0801763105

He, Q., Gao, Y., Zhang, L., Zhang, Z., Gao, F., Ji, X., Li, Y., Shi, J., 2011. A pH-responsive mesoporous silica nanoparticles-based multi-drug delivery system for overcoming multi-drug resistance. Biomaterials $32,7711-$ 7720. https://doi.org/10.1016/j.biomaterials.2011.06.066

Heurtault, B., Saulnier, P., Pech, B., Venier-Julienne, M.-C., Proust, J.-E., Phan-Tan-Luu, R., Benoît, J.-P., 2003. The influence of lipid nanocapsule composition on their size distribution. Eur. J. Pharm. Sci. 18, 55-61. https://doi.org/https://doi.org/10.1016/S0928-0987(02)00241-5

Hong, S.P., Wen, J., Bang, S., Park, S., Song, S.Y., 2009. CD44-positive cells are responsible for gemcitabine 
resistance in pancreatic cancer cells. Int. J. Cancer 125, 2323-31. https://doi.org/10.1002/ijc.24573

Immordino, M.L., Brusa, P., Rocco, F., Arpicco, S., Ceruti, M., Cattel, L., 2004. Preparation, characterization, cytotoxicity and pharmacokinetics of liposomes containing lipophilic gemcitabine prodrugs. J. Control. Release 100, 331-346. https://doi.org/10.1016/j.jconrel.2004.09.001

Ito, E., Yip, K.W., Katz, D., Fonseca, S.B., Hedley, D.W., Chow, S., Xu, G.W., Wood, T.E., Bastianutto, C., Schimmer, A.D., Kelley, S.O., Liu, F.-F., 2009. Potential Use of Cetrimonium Bromide as an Apoptosis-Promoting Anticancer Agent for Head and Neck Cancer. Mol. Pharmacol. 76, 969-983. https://doi.org/10.1124/mol.109.055277

Jakubiak, P., Thwala, L.N., Cadete, A., Préat, V., Alonso, M.J., Beloqui, A., Csaba, N., 2017. Solvent-free protamine nanocapsules as carriers for mucosal delivery of therapeutics. Eur. Polym. J. 93, 695-705. https://doi.org/10.1016/j.eurpolymj.2017.03.049

Janes, K.A., Fresneau, M.P., Marazuela, A., Fabra, A., Alonso, M.J., 2001. Chitosan nanoparticles as delivery systems for doxorubicin. J. Control. Release 73, 255-267. https://doi.org/10.1016/S0168-3659(01)00294-2

Jiang, W., Kim, B.Y.S., Rutka, J.T., Chan, W.C.W., 2008. Nanoparticle-mediated cellular response is size-dependent. Nat. Nanotechnol. 3, 145-150. https://doi.org/10.1038/nnano.2008.30

Klotz, L., Boccon-Gibod, L., Shore, N.D., Andreou, C., Persson, B.E., Cantor, P., Jensen, J.K., Olesen, T.K., Schröder, F.H., 2008. The efficacy and safety of degarelix: A 12-month, comparative, randomized, open-label, parallelgroup phase III study in patients with prostate cancer. BJU Int. 102, 1531-1538. https://doi.org/10.1111/j.1464410X.2008.08183.x

Lalloo, A., Chao, P., Hu, P., Stein, S., Sinko, P.J., 2006. Pharmacokinetic and pharmacodynamic evaluation of a novel in situ forming poly ( ethylene glycol ) -based hydrogel for the controlled delivery of the camptothecins 112, 333342. https://doi.org/10.1016/j.jconrel.2006.03.002

Lamprecht, A., Bouligand, Y., Benoit, J., 2002. New lipid nanocapsules exhibit sustained release properties for amiodarone. J. Control. Release 84, 59-68. https://doi.org/https://doi.org/10.1016/S0168-3659(02)00258-4

Laprise-Pelletier, M., Ma, Y., Lagueux, J., Côté, M.F., Beaulieu, L., Fortin, M.A., 2018. Intratumoral Injection of LowEnergy Photon-Emitting Gold Nanoparticles: A Microdosimetric Monte Carlo-Based Model. ACS Nano 12, 24822497. https://doi.org/10.1021/acsnano.7b08242

Lee, H., Fonge, H., Hoang, B., Reilly, R.M., Allen, C., 2010. The Effects of Particle Size and Molecular Targeting on the Intratumoral and Subcellular Distribution of Polymeric Nanoparticles. Mol. Pharm. 7, 1195-1208. https://doi.org/10.1021/mp100038h

Lee, J.W., Yang, S., Na, K., 2012. Gemcitabine-releasing polymeric films for covered self-expandable metallic stent in treatment of gastrointestinal cancer. Int. J. Pharm. 427, 276-283. https://doi.org/10.1016/j.ijpharm.2012.02.016

Lefebvre, G., Riou, J., Bastiat, G., Roger, E., Frombach, K., Gimel, J.C., Saulnier, P., Calvignac, B., 2017. Spontaneous nano-emulsification: Process optimization and modeling for the prediction of the nanoemulsion's size and polydispersity. Int. J. Pharm. 534, 220-228. https://doi.org/10.1016/j.ijpharm.2017.10.017

Lollo, G., Hervella, P., Calvo, P., Avilés, P., Guillén, M.J., Garcia-Fuentes, M., Alonso, M.J., Torres, D., 2015. Enhanced in vivo therapeutic efficacy of plitidepsin-loaded nanocapsules decorated with a new poly-aminoacid-PEG derivative. Int. J. Pharm. 483, 212-219. https://doi.org/10.1016/j.ijpharm.2015.02.028

Long, J., Zhang, Y., Yu, X., Yang, J., LeBrun, D.G., Chen, C., Yao, Q., Li, M., 2011. Overcoming drug resistance in pancreatic cancer. Expert Opin. Ther. Targets 15, 817-28. https://doi.org/10.1517/14728222.2011.566216

Lozano, M. V., Lollo, G., Alonso-Nocelo, M., Brea, J., Vidal, A., Torres, D., Alonso, M.J., 2013. Polyarginine nanocapsules: A new platform for intracellular drug delivery. J. Nanoparticle Res. 15, 1-15. https://doi.org/10.1007/s11051-013-1515-7

Mackey, J.R., Jam, R., Mani, S., Seiner, M., Mowles, D., Young, J.D., Belt, J. a, Crawford, C.R., Cass, C.E., 1998. Functional Nucleoside Transporters Are Required for Gemcitabine Influx and Manifestation of Toxicity in Cancer Cell Lines. Cancer Res. 58, 4349-4357.

Meerovich, G., Meerovich, I., Lukyanets, E., Oborotova, N., Derkacheva, V., Smirnova, Z., Pevgov, V., Zorin, A., 
Gurevich, D., Loschenov, V., Vorozhtsov, G., Baryshnikov, A., 2008. Influence of Liposome Size on Accumulation in Tumor and Therapeutic Efficiency of Liposomal Near-IR Photosensitizer for PDT based on Aluminum hydroxide tetra-3-phenylthiophthalocyanine. Nsti Nanotech, Tech. Proc. 2, 41-44.

Menger, F.M., Caran, K.L., 2000. Anatomy of a Gel. Amino Acid Derivatives That Rigidify Water at Submillimolar Concentrations. J. Am. Chem. Soc. 122, 11679-11691. https://doi.org/10.1021/ja0016811

Mitra, R.N., Das, P.K., 2008. In situ Preparation of Gold Nanoparticles of Varying Shape in Molecular Hydrogel of Peptide Amphiphiles. J. Phys. Chem. C 112, 8159-8166. https://doi.org/10.1021/jp712106d

620 Mohmeyer, N., Schmidt, H., 2005. A New Class of Low-Molecular-Weight Amphiphilic Gelators. Chem. Eur. J. 11, 863872. https://doi.org/10.1002/chem.200400716

Moore, T.L., Rodriguez-lorenzo, L., Hirsch, V., Balog, S., Urban, D., Jud, C., Rothen-rutishauser, B., Petri-fink, A., 2015. Chem Soc Rev media and impact on cellular interactions †. Chem. Soc. Rev. 44, 6287-6305. https://doi.org/10.1039/C4CS00487F

625 Mora-Huertas, C.E., Fessi, H., Elaissari, A, 2010. Polymer-based nanocapsules for drug delivery. Int. J. Pharm. 385 , 113-42. https://doi.org/10.1016/j.ijpharm.2009.10.018

Moysan, E., González-Fernández, Y., Lautram, N., Béjaud, J., Bastiat, G., Benoit, J. P., 2014. An innovative hydrogel of gemcitabine-loaded lipid nanocapsules: when the drug is a key player of the nanomedicine structure. Soft Matter. https://doi.org/10.1039/c3sm52781f

630 Nanda, J., Adhikari, B., Basak, S., Banerjee, A., 2012. Formation of hybrid hydrogels consisting of tripeptide and different silver nanoparticle-capped ligands: Modulation of the mechanical strength of gel phase materials. J. Phys. Chem. B 116, 12235-12244. https://doi.org/10.1021/jp306262t

Naskar, J., Palui, G., Banerjee, A., 2009. Tetrapeptide-based hydrogels: For encapsulation and slow release of an anticancer drug at physiological ph. J. Phys. Chem. B 113, 11787-11792. https://doi.org/10.1021/jp904251j

635 Nomura, T., Koreeda, N., Yamashita, F., Takakura, Y., Hashida, M., 1998. Effect of Particle Size and Charge on the Disposition of Lipid Carriers After Intratumoral Injection into Tissue-isolated Tumors. Pharm. Res. 15, $128-132$. https://doi.org/10.1023/A:1011921324952

Oyarzun-Ampuero, F. a., Rivera-Rodriguez, G.R., Alonso, M.J., Torres, D., 2013. Hyaluronan nanocapsules as a new vehicle for intracellular drug delivery. Eur. J. Pharm. Sci. 49, 483-490. https://doi.org/10.1016/j.ejps.2013.05.008

640 Pokuri, V.K., Fong, M.K., lyer, R., 2016. Octreotide and Lanreotide in Gastroenteropancreatic Neuroendocrine Tumors. Curr. Oncol. Rep. 18, 1-9. https://doi.org/10.1007/s11912-015-0492-7

Poletto, F.S., Jäger, E., Cruz, L., Pohlmann, A.R., Guterres, S.S., 2008. The effect of polymeric wall on the permeability of drug-loaded nanocapsules. Mater. Sci. Eng. C 28, 472-478. https://doi.org/10.1016/j.msec.2007.04.015

Pulido, J., Sobczak, A.J., Balzarini, J., Wnuk, S.F., 2014. Synthesis and cytostatic evaluation of 4-N-alkanoyl and 4-Nalkyl gemcitabine analogues. J. Med. Chem. 57, 191-203. https://doi.org/10.1021/jm401586a

Rivera-Rodriguez, G.R., Lollo, G., Montier, T., Benoit, J.P., Passirani, C., Alonso, M.J., Torres, D., 2013. In vivo evaluation of poly-I-asparagine nanocapsules as carriers for anti-cancer drug delivery. Int. J. Pharm. 458, 83-89. https://doi.org/10.1016/j.ijpharm.2013.09.038

Saberi, A.H., Fang, Y., McClements, D.J., 2013. Fabrication of vitamin E-enriched nanoemulsions: Factors affecting particle size using spontaneous emulsification. J. Colloid Interface Sci. 391, 95-102. https://doi.org/10.1016/j.jcis.2012.08.069

Sangeetha, N.M., Maitra, U., 2005. Supramolecular gels: Functions and uses. Chem. Soc. Rev. 34, $821-836$. https://doi.org/10.1039/b417081b

Saw, W.S., Ujihara, M., Chong, W.Y., Voon, S.H., Imae, T., Kiew, L.V., Lee, H.B., Sim, K.S., Chung, L.Y., 2018. Sizedependent effect of cystine/citric acid-capped confeito-like gold nanoparticles on cellular uptake and photothermal cancer therapy. Colloids Surfaces B Biointerfaces 161, 365-374. https://doi.org/10.1016/j.colsurfb.2017.10.064 
Şenyiğit, Z., Karavana, S., İlem-Özdemir, D., Çalışkan, Ç., Waldner, C., Şen, S., Bernkop-Schnürch, A., Baloğlu, E., 2015. Design and evaluation of an intravesical delivery system for superficial bladder cancer : preparation of gemcitabine $\mathrm{HCl}-$ loaded chitosan - thioglycolic acid nanoparticles and comparison of chitosan / poloxamer gels as carriers. Int. J. Nanomedicine 10, 6493-6507. https://doi.org/10.2147//JN.S93750

Singh, M., Kundu, S., Reddy M, A., Sreekanth, V., Motiani, R.K., Sengupta, S., Srivastava, A., Bajaj, A., 2014. Injectable small molecule hydrogel as a potential nanocarrier for localized and sustained in vivo delivery of doxorubicin. Nanoscale 6, 12849-12855. https://doi.org/10.1039/C4NR04064C

Skilling, K.J., Kellam, B., Ashford, M., Bradshaw, T.D., Marlow, M., 2016. Developing a self-healing supramolecular nucleoside hydrogel. Soft Matter 12, 8950-8957. https://doi.org/10.1039/c6sm01779g

Skilling, K.J., Stocks, M.J., Kellam, B., Ashford, M., Bradshaw, T.D., Burroughs, L., Marlow, M., 2018. NucleosideBased Self-Assembling Drugs for Localized Drug Delivery. ChemMedChem 13, 1098-1101. https://doi.org/10.1002/cmdc.201800063

Song, F., Zhang, L., Shi, J., Li, N., 2010. Viscoelastic and fractal characteristics of a supramolecular hydrogel hybridized with clay nanoparticles. Colloids Surfaces B Biointerfaces 81, 486-491. https://doi.org/10.1016/j.colsurfb.2010.07.044

Steinberg, M., 2009. Degarelix: A Gonadotropin-Releasing Hormone Antagonist for the Management of Prostate Cancer. Clin. Ther. 31, 2312-2331. https://doi.org/10.1016/j.clinthera.2009.11.009

Storm, G., Belliot, S., Daemenb, T., Lasic, D.D., 1995. Surface modification of nanoparticles to oppose uptake by the mononuclear phagocyte system. Adv. Drug Deliv. Rev. 17, 31-48. https://doi.org/https://doi.org/10.1016/0169409X(95)00039-A

Strasser, J., Fung, L., Saltzman, W.M., Fung, L.K., 1995. Distribution of 1,3-bis(2-Chloroethyl)-1-Nitrosourea and tracers in the Rabbit Brain After Interstitial and Tracers Delivery by Biodegradable polymer implants. J. Pharmacol. Exp. Ther. 275, 1647-1655.

Tan, S.W., Billa, N., Roberts, C.R., Burley, J.C., 2010. Surfactant effects on the physical characteristics of Amphotericin B-containing nanostructured lipid carriers. Colloids Surfaces A Physicochem. Eng. Asp. 372, 73-79. https://doi.org/10.1016/j.colsurfa.2010.09.030

Tian, R., Niu, R., 2014. The development of low-molecular weight hydrogels for applications in cancer therapy. Nanoscale 6, 3474-3482. https://doi.org/10.1039/c3nr05414d

Torrecilla, D., Lozano, M. V, Lallana, E., Neissa, J.I., Novoa-Carballal, R., Vidal, A., Fernandez-Megia, E., Torres, D., Riguera, R., Alonso, M.J., Dominguez, F., 2013. Anti-tumor efficacy of chitosan-g-poly(ethylene glycol) nanocapsules containing docetaxel: anti-TMEFF-2 functionalized nanocapsules vs. non-functionalized nanocapsules. Eur. J. Pharm. Biopharm. 83, 330-7. https://doi.org/10.1016/j.ejpb.2012.10.017

Vlieghe, P., Lisowski, V., Martinez, J., Khrestchatisky, M., 2010. Synthetic therapeutic peptides: science and market. Drug Discov. Today 15, 40-56. https://doi.org/10.1016/j.drudis.2009.10.009

Wang, H., Wei, J., Yang, C., Zhao, H., Li, D., Yin, Z., Yang, Z., 2012. The inhibition of tumor growth and metastasis by self-assembled nanofibers of taxol. Biomaterials 33 , 5848-5853. https://doi.org/10.1016/j.biomaterials.2012.04.047

Wang, H., Yang, C., Wang, L., Kong, D., Zhang, Y., Yang, Z., 2011. Self-assembled nanospheres as a novel delivery system for taxol: a molecular hydrogel with nanosphere morphology. Chem. Commun. 47, 4439. https://doi.org/10.1039/c1cc10506j

Weizman, N., Krelin, Y., Shabtay-Orbach, a, Amit, M., Binenbaum, Y., Wong, R.J., Gil, Z., 2014. Macrophages mediate gemcitabine resistance of pancreatic adenocarcinoma by upregulating cytidine deaminase. Oncogene 33, 38123819. https://doi.org/10.1038/onc.2013.357

Wickremsinhe, E., Bao, J., Smith, R., Burton, R., Dow, S., Perkins, E., 2013. Preclinical absorption, distribution, metabolism, and excretion of an oral amide prodrug of gemcitabine designed to deliver prolonged systemic exposure. Pharmaceutics 5, 261-276. https://doi.org/10.3390/pharmaceutics5020261

Wolinsky, J.B., Colson, Y.L., Grinstaff, M.W., 2012. Local drug delivery strategies for cancer treatment: gels, 
nanoparticles, polymeric films, rods, and wafers. J. Control. Release 159, 14-26. https://doi.org/10.1016/j.jconrel.2011.11.031

Youm, I., Agrahari, V., Murowchick, J.B., Youan, B.B.C., 2014. Uptake and Cytotoxicity of Docetaxel-Loaded Hyaluronic Acid-Grafted Oily Core Nanocapsules in MDA-MB 231 Cancer Cells. Pharm. Res. 31, 2439-2452. https://doi.org/https://doi.org/10.1007/s11095-014-1339-x

710 Zanotto-Filho, A., Coradini, K., Braganhol, E., Schröder, R., De Oliveira, C.M., Simoes-Pires, A., Battastini, A.M.O., Pohlmann, A.R., Guterres, S.S., Forcelini, C.M., Beck, R.C.R., Moreira, J.C.F., 2013. Curcumin-loaded lipid-core nanocapsules as a strategy to improve pharmacological efficacy of curcumin in glioma treatment. Eur. J. Pharm. Biopharm. 83, 156-167. https://doi.org/10.1016/j.ejpb.2012.10.019 
